\title{
Electroanalytical Method for Determination of Trace Metals in Struvite Using Electrochemically Treated Screen-Printed Gold Electrodes
}

\author{
Maria L. S. Vasconcellos, ${ }^{a}$ Diego P. Rocha, ${ }^{b}$ Sílvia V. F. Castro, ${ }^{b}$ Luiz R. G. Silva, ${ }^{a}$ \\ Rodrigo A. A. Muñoz, ${ }^{*}, b$ Marcos B. J. G. Freitas ${ }^{a}$ and Rafael Q. Ferreira*,a \\ ${ }^{a}$ Departamento de Química, Universidade Federal do Espírito Santo, 29075-910 Vitória-ES, Brazil \\ ${ }^{b}$ Instituto de Química, Universidade Federal do Uberlândia, 38400-902 Uberlândia-MG, Brazil
}

\begin{abstract}
We present an electroanalytical method using square-wave anodic stripping voltammetry on electrochemically-treated screen-printed gold electrodes to the simultaneous determination of lead(II), copper(II) and mercury(II) in struvite (natural fertilizer produced from urine). Electrochemical treatment via cyclic voltammetry of the working electrodes increased surface rugosity that improved the electroanalytical responses for the three metals. Under optimized conditions and using a deposition time of $90 \mathrm{~s}$, the proposed method presented the following limit of detection values: $1.3 \mu \mathrm{g} \mathrm{L} \mathrm{L}^{-1}$ for lead(II), $2.0 \mu \mathrm{g} \mathrm{L} \mathrm{L}^{-1}$ for copper(II) and $0.9 \mu \mathrm{g} \mathrm{L} \mathrm{L}^{-1}$ for mercury(II). Struvite samples were easily dissolved in supporting electrolyte solution $\left(0.05 \mathrm{~mol} \mathrm{~L}^{-1} \mathrm{HCl}\right)$. Satisfactory recovery values between 91 and $111 \%$ were obtained for the analysis of spiked samples. Hence, we can infer that the proposed electroanalytical method is an effective alternative for the determination of trace metals, since it provides precise and accurate direct analyses, with rapid responses without interference from sample matrix and enabling in field analysis.
\end{abstract}

Keywords: natural fertilizer, struvite, stripping voltammetry, screen-printed gold electrode, trace metals

\section{Introduction}

At the end of the 40s, a historical transformation occurred in the world, called "Green Revolution". During this period, agriculture has undergone some changes regarding technological and industrial advances that have driven food production. ${ }^{1,2}$ On the other hand, new problems emerged due to these new agricultural practices, among them the contamination by the disorderly use of agrochemicals. $^{3}$

In this context, organic agriculture has contributed to the economic development of world in a significant way, gaining more space in the agribusiness market. Therefore, it is fundamental that, in addition to current legislation regulating this form of cultivation, the quality control of all the inputs and/or fertilizers used during planting should also be carried out to ensure that they are free of contaminants.

One of the natural fertilizers that can be used in organic agriculture is struvite, scientifically known as magnesium ammonium phosphate hexahydrate $\left(\mathrm{MgNH}_{4} \mathrm{PO}_{4} \cdot 6 \mathrm{H}_{2} \mathrm{O}\right)$, which can be precipitated from human or bovine urine

*e-mail: munoz@ufu.br; rafaeldeqf@gmail.com by means of addition of magnesium oxide. ${ }^{4}$ Urine is suitable for the production of struvite due to its large number of macronutrients such as nitrogen, phosphorus and potassium, which are essential for the cultivation of various food crops. ${ }^{5-7}$ Consequently, this input allows the reuse of nutrients directly as fertilizers contributing to a sustainable environment. ${ }^{7,8}$

However, struvite may contain trace metals from the urine precipitation process, as reported in the studies of Ryu et al. ${ }^{9}$ and Antonini et al. ${ }^{10}$ who employed inductively coupled plasma-optical emission spectroscopy (ICP OES). In these studies, several metals were identified, such as aluminum, arsenic, boron, barium, cadmium, chromium, copper, iron, lithium, lead, manganese, molybdenum, mercury, niobium, nickel, silicon, strontium, vanadium and zinc with concentrations found at the $\mu \mathrm{g} \mathrm{g}^{-1}$ level. Among the elements cited above, the present study focused on the determination of lead(II), copper(II) and mercury(II) because these metals were found at higher concentrations in plants grown with struvite and especially due to their high toxicity. ${ }^{9,10}$ Thus, these environmental micro-contaminants have been taken into account as a potential threat to the contamination of soil, food crops and water resources. ${ }^{11}$ 
Therefore, it is essential to carry out the quality control of struvite in order to guarantee a product free of contaminants, and to add more value to the use of this input in organic agriculture, as well as to ensure the quality of the final product. Electroanalytical methods, in particular, square-wave anodic stripping voltammetry (SWASV), have high selectivity and detectability (concentration ca. $10^{-12} \mathrm{~mol} \mathrm{~L}^{-1}$ ), low cost when compared to chromatographic and spectroscopic techniques, and are widely used for the analysis of trace metals as well as multielement determination. SWASV analysis presents lower influence of interferents, reduced consumption of reagents, which leads to a lower environmental impact caused by the chemical residues generated and can be used in loco in an efficient and less expensive way. ${ }^{12}$

In order to further enhance the sensitivity of SWASV and to miniaturize electrochemical systems, the screenprinted electrodes (SPEs) appear as an alternative to conventional electrodes, since these devices are low cost, and reproducible. In addition, it is possible to use various materials in their construction, such as carbon, gold, and platinum, which can be modified (by film, enzyme and antigen-antibody) or unmodified. ${ }^{13-15}$

Among these materials, we can highlight the screenprinted gold electrodes (SPGE) that have been applied in the detection of toxic metals such as lead(II), copper(II) and mercury(II) combined with the SWASV technique in different matrices, such as fluvial waters, ${ }^{16}$ industrial water and rainwater, ${ }^{17}$ bioethanol, ${ }^{18}$ and in fish oil capsules. ${ }^{19}$ Furthermore, no work was found in the literature citing the determination of the metals lead(II), copper(II), and mercury(II) in fertilizers (including struvite), which presents a different sample matrix compared with previous analyzed samples. Hence, a miniaturized analytical system for on-site analysis of fertilizers applied for the quantification of contaminants present in struvite is the motivation of this research. In this context, the aim of the present work was to develop a sensitive, fast, low cost method that can be applied on site using an SPGE for the simultaneous determination of trace metals (lead(II), copper(II), and mercury(II)) via SWASV after a simple sample preparation (dilution in the electrolytes).

\section{Experimental}

\section{Reagents and solutions}

All solutions used in the experiments were prepared from analytical-grade reagents and high-purity water (resistivity $\geq 18 \mathrm{M} \Omega \mathrm{cm}, 25^{\circ} \mathrm{C}$ ) obtained from a Milli-Q water purification system with reverse osmosis (Millipore ${ }^{\circledR}$, Bedford, USA). Hydrochloric acid (37\%), were obtained from Vetec ${ }^{\circledR}$ (Rio de Janeiro, Brazil). Aqueous standard solution of lead(II), copper(II), and mercury(II) (1000 mg L ${ }^{-1}$ ) were purchased from Specsol ${ }^{\circledast}$ (São Paulo, Brazil). For the test of interferents, $1000 \mathrm{mg} \mathrm{L}^{-1}$ standard solutions of iron(III), nickel(II), zinc(II), cadmium(II), and cobalt(II) (Sigma-Aldrich ${ }^{\circledR}$, Missouri, USA) were used.

\section{Sample preparation}

Struvite sample was obtained from the Núcleo de Bioengenharia Aplicada ao Saneamento of Universidade Federal do Espírito Santo, in which it was processed by a reactor with a capacity of $450 \mathrm{~L}$ of urine, coupled to a centrifugal pump used to mix the magnesium oxide solution.

Exactly $60 \mathrm{mg}$ of struvite was macerated and dissolved in $100 \mathrm{~mL}$ of $0.05 \mathrm{~mol} \mathrm{~L}^{-1} \mathrm{HCl}$ (supporting electrolyte) and left in an ultrasonic bath (Eco-sonics ${ }^{\circledR}$, São Paulo, Brazil) until the complete solubilization of the fertilizer. To evaluate the accuracy of the proposed protocol, a recovery test was performed using a sample fortified with $10 \mu \mathrm{g} \mathrm{L}^{-1}$ of lead(II), copper(II) and mercury(II) in $0.05 \mathrm{~mol} \mathrm{~L}^{-1} \mathrm{HCl}$.

\section{Instrumentation, electrochemical cell and electrodes}

Electrochemical recordings were conducted using a $\mu$-Autolab type III potentiostat (EcoChemie ${ }^{\circledR}$, Utrecht, The Netherlands), along with a magnetic stirrer model 728 (Metrohm $^{\circledR}$, Herisau, Switzerland). One connector cable (DRP-CAC) acquired from DropSens ${ }^{\circledR}$ (Oviedo, Spain) was used to establish the interface between potentiostat and SPGEs. Additionally, a $10 \mathrm{~mL}$ electrochemical cell, made of borosilicate glass, was adapted for SPGEs.

SPGEs were purchased from DropSens ${ }^{\circledR}$ (Oviedo, Spain). Each strip contains three electrodes screen-printed on the same planar ceramic platform, consisting of a gold disk shaped (4 mm diameter) working electrode, a gold counter electrode, a silver pseudo-reference electrode. SPGE was manufactured at a low cure temperature (SPGE-BT) resulting in a medium roughness of $2.10 \mu \mathrm{m}$, according to the manufacturer.

\section{Electrochemical measurements}

The treatment of the SPGE before analysis (native electrodes) was performed according to the procedures previously described. ${ }^{18}$ Baseline stabilization was obtained by cyclic voltammetry ( 15 cycles) in a potential range of -0.6 to $0.6 \mathrm{~V}$, at $0.05 \mathrm{~V} \mathrm{~s}^{-1}$ in $0.05 \mathrm{~mol} \mathrm{~L}^{-1} \mathrm{HCl}$. After conditioning, the electrode response remained stable, with no baseline noise and low background currents. 
The optimization of SWASV parameters was based on univariate experiments. Parameters including potential and time of deposition, stirring rate, step potential, modulation amplitude and frequency were studied using a multielement standard solution containing $10 \mu \mathrm{g} \mathrm{L}-1$ of each metal ion and $0.05 \mathrm{~mol} \mathrm{~L}^{-1} \mathrm{HCl}$ as supporting electrolyte. In summary, the evaluated ranges and the optimized SWASV parameters for the simultaneous determination of the three metals are listed in Table 1. Conditioning step (cleaning), previous to deposition and scanning, was used to restore the baseline and avoid SPGE poisoning. All electrochemical measurements were carried out in the presence of dissolved oxygen and at room temperature. The standard addition method was used for construction of the standard curves of each metal.

SWASV voltammetric recordings were baseline treated using the moving average algorithm of NOVA (Metrohm ${ }^{\circledR}$, Utrecht, The Netherlands).

\section{Surface characterization of screen-printed gold electrode}

Scanning electron microscopic (SEM) images were obtained using a $20 \mathrm{kV}$ Vega 3 TESCAN $^{\circledR}$ (Fuveau, France) scanning electron microscope, and to identify the contaminants contained on the working electrode surface of SPGE, a dispersive energy X-ray spectroscopy (EDS) detector (Oxford Instruments ${ }^{\circledast}$, Bucks, England) with a voltage of $10 \mathrm{kV}$ was used. Atomic force microscope (AFM) images of SPGEs (before and after electrochemical treatment) were obtained by a Shimadzu ${ }^{\circledR}$ (Kyoto, Japan) scanning probe microscopy (SPM-9600) in dynamic (noncontact) mode and using a silicone tip (BudgetSensors ${ }^{\circledR}$, Sofia, Bulgaria) with radius of curvature $<10 \mathrm{~nm}$, force constant $(\mathrm{K})=40 \mathrm{~N} \mathrm{~m}^{-1}$ and frequency $300 \mathrm{kHz}$.

\section{Results and Discussion}

\section{Electrode treatment}

Initially, SPGE was subjected to a cleaning conditioning in order to remove the organic constituents of the metallic "ink", as well as some possible contaminants. ${ }^{17}$ Thus, the SPGE was submitted to an electrochemical pretreatment via cyclic voltammetry (15 cycles), as indicated in Figure 1a. SWASV measurements for the detection of lead(II), copper(II) and mercury(II) before and after the electrochemical treatment are shown in Figure 1b. The supporting electrolyte of $0.05 \mathrm{~mol} \mathrm{~L}^{-1} \mathrm{HCl}$ was chosen based on some preliminary studies ${ }^{18,20,21}$ which pointed out that a constant concentration of chloride ions improves the sensitivity for the determination of copper(II), lead(II) and mercury(II) on gold electrodes and simultaneously is necessary for the stabilization of the pseudo-reference electrode. ${ }^{14}$ Thus, $\mathrm{HCl}$ was determined as a supporting electrolyte to be used in all subsequent analyses. Furthermore, the upper applied potential for the treatment of the gold electrode in the presence of chloride ions should not reach $+1.00 \mathrm{~V}$ due to the formation of $\mathrm{HAuCl}_{4}$. For this reason, the applied potential was $+0.6 \mathrm{~V}$ ( $v s$. pseudo $\mathrm{Ag} / \mathrm{AgCl})$.

In Figure 1a, a reduction peak at $-0.12 \mathrm{~V}$ and an oxidation peak at $+0.02 \mathrm{~V}$ that do not refer to any of the metals of interest in this work were observed. According to Almeida et al.,$^{18}$ these peaks can be attributed to the contamination of silver ink that is used in the manufacture of SPGE. In order to confirm the presence of silver as a contaminant on SPGE surface, an investigative study using EDS analysis and cyclic voltammetry in the presence of silver nitrate was carried out (shown in Figures S1 and S2 in Supplementary Information (SI) section). EDS did not show the presence of silver, probably due to the low sensitivity of this technique for elemental determination (Figure S1). On the other hand, cyclic voltammetry of the SPGE, after the addition of silver nitrate standard solution, showed the increase in current at the potential values close to both oxidation and reduction processes already observed in the cyclic voltammogram of the blank. Therefore, this result presents a strong evidence that the unexpected peaks come from the silver ink used in the manufacture of SPGE. In addition, it can be observed an intense reduction peak starting at $-0.20 \mathrm{~V}$, which can be attributed to the reduction reaction

Table 1. SWASV parameters for the determination of lead(II), copper(II), and mercury(II)

\begin{tabular}{lccc}
\hline & Electrochemical parameter & Studied interval & Optimized value \\
\hline \multirow{2}{*}{ Deposition step } & deposition potential / V & 0.1 to -0.6 & -0.4 \\
& deposition time / s & 30 to 240 & 90 \\
& stirring rate / rpm & 500 to 2500 & 0.001 to 0.008 \\
SWV step & step potential / V & 0.01 to 0.1 & 0.002 \\
& modulation amplitude / V & 10 to 30 & 0.03 \\
\hline
\end{tabular}

SWV: square-wave voltammetry. 

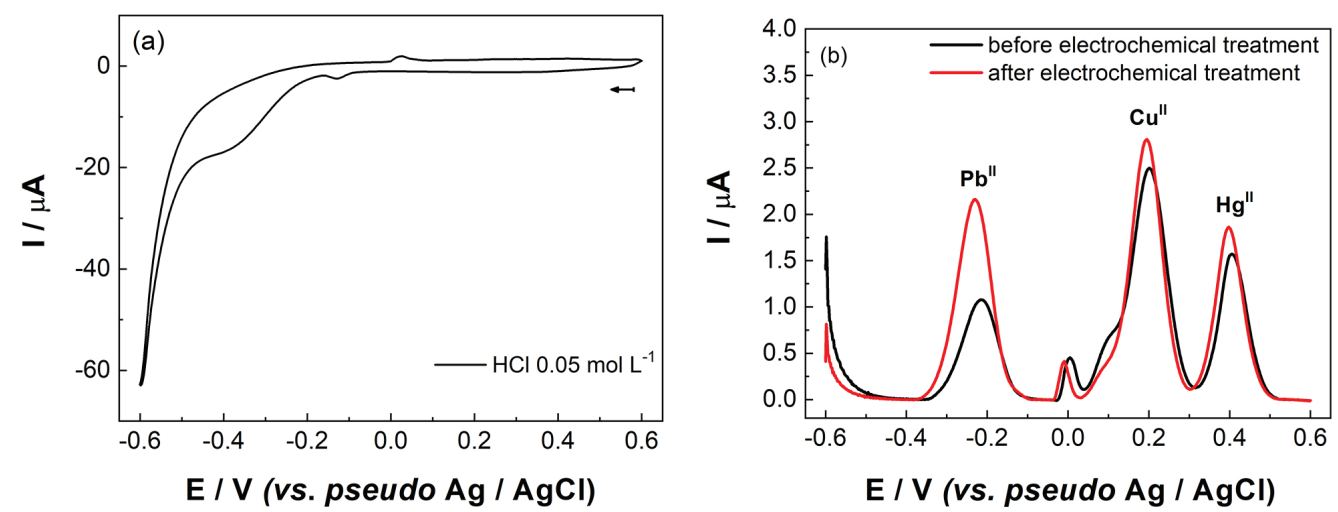

Figure 1. (a) Voltammetric profile of SPGE in $0.05 \mathrm{~mol} \mathrm{~L}^{-1} \mathrm{HCl}$. Scan rate $=0.05 \mathrm{~V} \mathrm{~s}^{-1}$. Start and direction of the scan $(\leftrightarrow)$; (b) background-corrected SWASV recordings in the presence of $30 \mu \mathrm{g} \mathrm{L}^{-1}$ of lead(II), copper(II) and mercury(II) before (一) and after (一) the electrochemical treatment via cyclic voltammetry. SWASV parameters: $-0.4 \mathrm{~V}$ (deposition potential); $90 \mathrm{~s}$ (deposition time); $1500 \mathrm{rpm}$ (stirring rate); $0.03 \mathrm{~V}$ (modulation amplitude); $0.002 \mathrm{~V}$ (step potential) and $10 \mathrm{~Hz}$ (frequency). Background electrolyte: $0.05 \mathrm{~mol} \mathrm{~L}^{-1} \mathrm{HCl}$.

of oxygen as the solution was not purged with nitrogen to remove the dissolved oxygen in solution. ${ }^{22}$ Figure $1 \mathrm{~b}$ reveals that the peak current values $\left(\mathrm{I}_{\text {peak }}\right)$ increase 102, 13 and $18 \%$ for lead(II), copper(II) and mercury(II), respectively, after the electrochemical pretreatment of the SPGE.

Next, AFM images (Figure 2) of the SPGE before and after the electrochemical treatment were obtained to shed light on the improvement of analytical responses after the treatment.

The AFM images indicate that the electrochemical pretreatment promotes an increase in roughness of the surface of working electrode, as well as their respective functionalities, as shown in Figure 2. Comparing Figures 2a and $2 \mathrm{~b}$, we can observe that after the electrochemical pretreatment of the SPGE there was an increase in the roughness of the electrode surface of $1.12 \mu \mathrm{m}$. SEM images of the SPGE before and after treatment also revealed increase in rugosity. Figure S3 (SI section) shows the respective images and histograms and an average increase of $0.15 \mu \mathrm{m}$ in the surface roughness of the electrode was verified. Therefore, the increase in analytical response for the three metals are likely due to the higher electroactive area of the working electrode (higher roughness of the

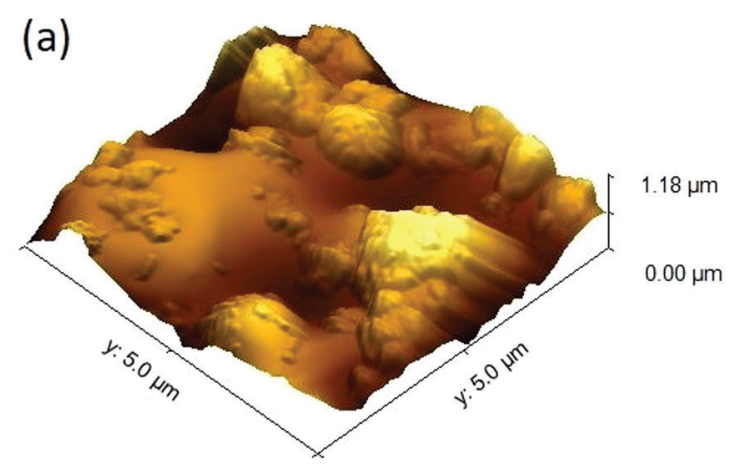

surface) obtained after the electrochemical treatment, which provides a larger number of sites to metal accumulation during the deposition step.

\section{Optimization of the SWASV parameters}

The optimization of SWASV experimental parameters was performed based on a previous work. ${ }^{18}$ Thus, the study was started using a frequency of $10 \mathrm{~Hz}$, modulation amplitude of $0.03 \mathrm{~V}$ and step potential of $0.004 \mathrm{~V}$. The values used for the electrode cleaning potential and deposition potential were $+0.55 \mathrm{~V}$ for $60 \mathrm{~s}$ and $-0.50 \mathrm{~V}$ for $90 \mathrm{~s}$, respectively. These parameters were selected based on the potential window of SPGE for the simultaneous determination of lead(II), copper(II) and mercury(II) as previously reported. ${ }^{18}$

Optimization was initiated with the study of anodic stripping voltammetry (ASV) parameters (deposition potential, stirring rate and deposition time) for the simultaneous determination of three metals, Figures 3a, 3b, and $3 \mathrm{c}$, respectively (the corresponding SWASV recordings are presented in Figure S4, SI section). In Figure 3a we can observe the peak currents for lead(II) presented maximum

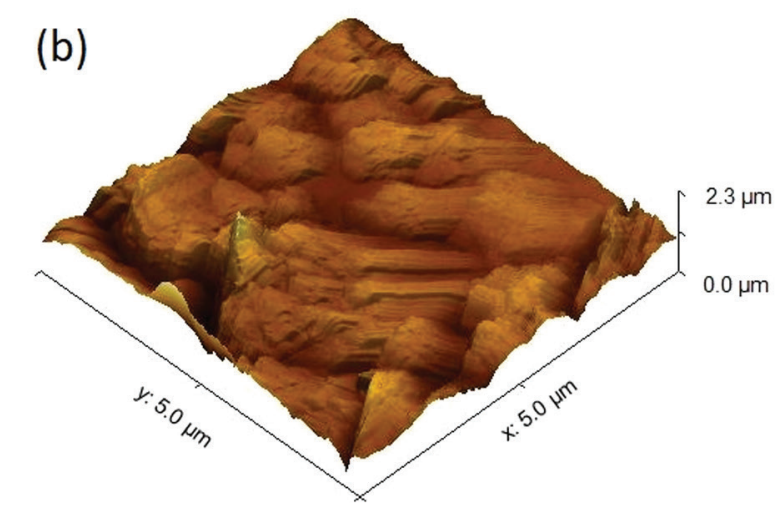

Figure 2. Morphology of SPGE via AFM (a) before and (b) after the electrochemical pretreatment. 
values at more negative potentials. For copper(II) the peak currents increased linearly from 0 to $-0.3 \mathrm{~V}$, whereas for mercury(II) there was a small variation of the peak current between -0.6 to $+0.1 \mathrm{~V}$. Thus, the potential chosen for the pre-concentration step was $-0.4 \mathrm{~V}$, since a low standard deviation and highest peak current $\left(\mathrm{I}_{\text {peak }}\right)$ were obtained for the simultaneous determination of the three metals.

The stirring in ASV determinations increases the mass transfer of trace metals towards the working electrode surface during the deposition step, and consequently the metal detectability improves. Thus, it causes the reduction of the thickness of the diffusion layer obtained by increasing of stirring rate. ${ }^{23}$ Hence, the stirring rate was also evaluated in the range of 500 to $2500 \mathrm{rpm}$. Figure $3 \mathrm{~b}$ shows that the $\mathrm{I}_{\text {peak }}$ for lead(II) and copper(II) increases linearly but has a lower slope for mercury(II). The selected value was $1500 \mathrm{rpm}$, which satisfies the simultaneous determination of the three metals of interest with the lowest standard deviation.

For the optimization of deposition time, the studies were performed in the range of 30 to $240 \mathrm{~s}$. Figure $3 \mathrm{c}$ shows an increase in $\mathrm{I}_{\text {peak }}$ for lead(II) and copper(II) in the range between 60 and $150 \mathrm{~s}$. On the other hand, $\mathrm{I}_{\text {peak }}$ remained practically constant for mercury(II) in the range from 30 to $180 \mathrm{~s}$. According to Bernalte et al. ${ }^{24}$ that behavior is due to the fact that $\mathrm{Hg}$ saturates quickly the SPGE surface, a factor that probably derives from the nature of the gold ink used in the construction of the electrode. Consequently, the optimal value chosen for the deposition time was $90 \mathrm{~s}$, since this value provides a better analytical frequency with a satisfactory detectability.

After selecting the ASV parameters, other parameters of the system were evaluated, such as step, modulation amplitude and frequency of square-wave voltammetry (SWV). Thus, Figure 4, shows that the increase in frequency directly influences the intensity of the $\mathrm{I}_{\text {peak }}$. However, at frequencies higher than $10 \mathrm{~Hz}$, we can observe a peak enlargement for copper(II), and low resolution for the mercury(II) peak, which causes less sensitivity of the method (Figure 4a). Consequently, we chose to work at a frequency of $10 \mathrm{~Hz}$, since this value satisfies the study of the three metals simultaneously.

Then, the study was carried out for modulation amplitude optimization, a parameter that directly influences the height and width of the peaks. Figure $4 \mathrm{c}$ shows that the values above $0.04 \mathrm{~V}$ of modulation amplitude generated a greater peak enlargement for lead(II) and mercury(II). Thus, from the SWASV recordings, in association with the study of the variation of the $\mathrm{I}_{\text {peak }}$ versus modulation amplitude (Figure 4d) we evaluated the optimal value between the measurements of 0.01 to $0.04 \mathrm{~V}$. Considering that at $0.04 \mathrm{~V}$ it was obtained larger deviation, the best value of the analyzed parameter was $0.03 \mathrm{~V}$, which presented the best analytical signal within the range of the optimal values under study.

Finally, the optimization of the step potential was carried out. The step potential is a parameter that directly affects the scan rate of the SWV, significantly improving the sensitivity of the analyses. ${ }^{24}$ However, it can promote enlargement of the peaks, as we can see in Figure 4e between potentials of 0.003 to $0.008 \mathrm{~V}$. As a function of the values presented in Figures 4e and 4f, we choose a step potential of $0.002 \mathrm{~V}$ as the optimum value, since it provided better analytical response for the metals of interest.

\section{Evaluation of electrode stability}

After the definition of the best experimental parameters, a study was carried out to evaluate the stability of the SPGE, as indicated in Figure 5, that shows the variation of the peak current as a function of the number of measurements $(\mathrm{n}=11)$.

In this plot we can observe that during the first 10 scans, the electrode presented a good stability, presenting
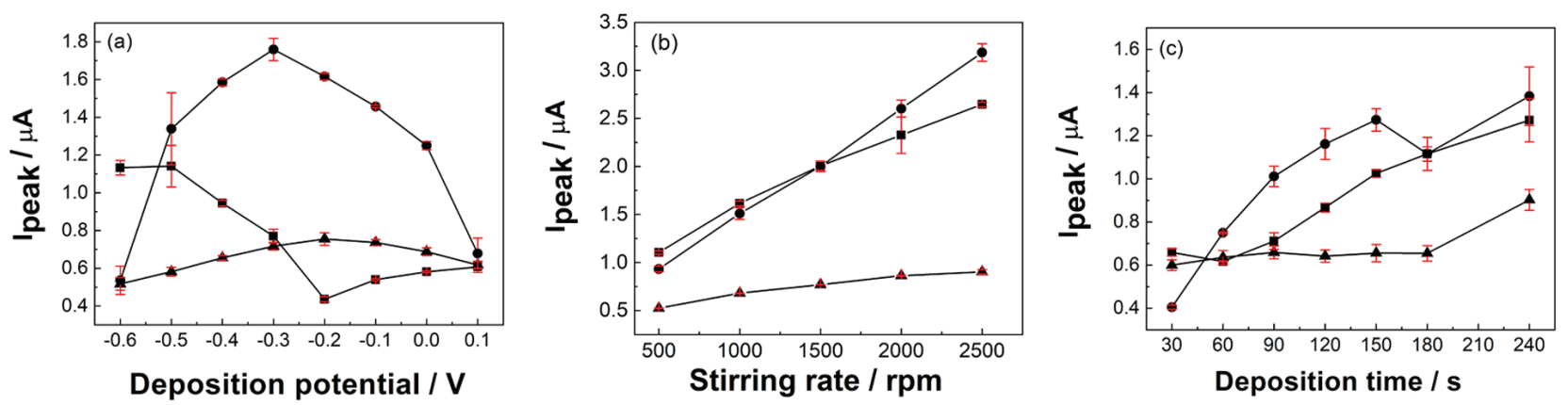

Figure 3. (a) Variation of the peak current $\left(\mathrm{I}_{\text {peak }}\right)$ versus deposition potential. SWASV parameters: $90 \mathrm{~s}$ (deposition time); $1000 \mathrm{rpm}$ (stirring rate); $0.004 \mathrm{~V}$ (step potential); $0.03 \mathrm{~V}$ (modulation amplitude) and $10 \mathrm{~Hz}$ (frequency); (b) variation of the peak current $\left(\mathrm{I}_{\text {peak }}\right)$ versus stirring rate. SWASV parameters: $-0.4 \mathrm{mV}$ (deposition potential); $90 \mathrm{~s}$ (deposition time); $0.004 \mathrm{~V}$ (step potential); $0.03 \mathrm{~V}$ (modulation amplitude) and $10 \mathrm{~Hz}$ (frequency); (c) variation of the peak current $\left(\mathrm{I}_{\text {peak }}\right.$ ) versus deposition time. SWASV parameters: $-0.4 \mathrm{~V}$ (deposition potential); $1500 \mathrm{rpm}$ (stirring rate); $0.004 \mathrm{~V}$ (step potential); $0.03 \mathrm{~V}$

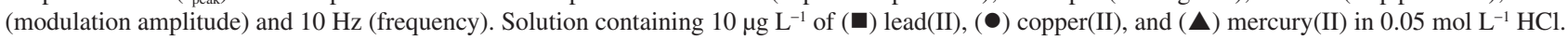



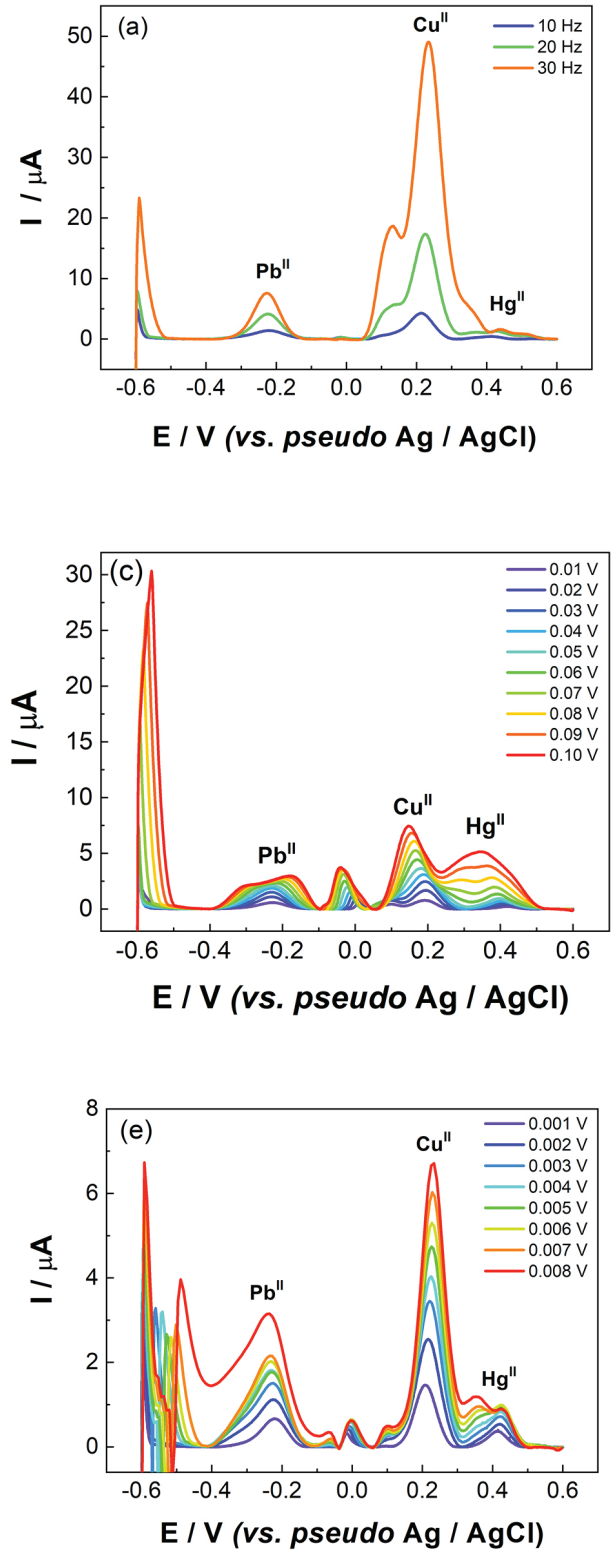
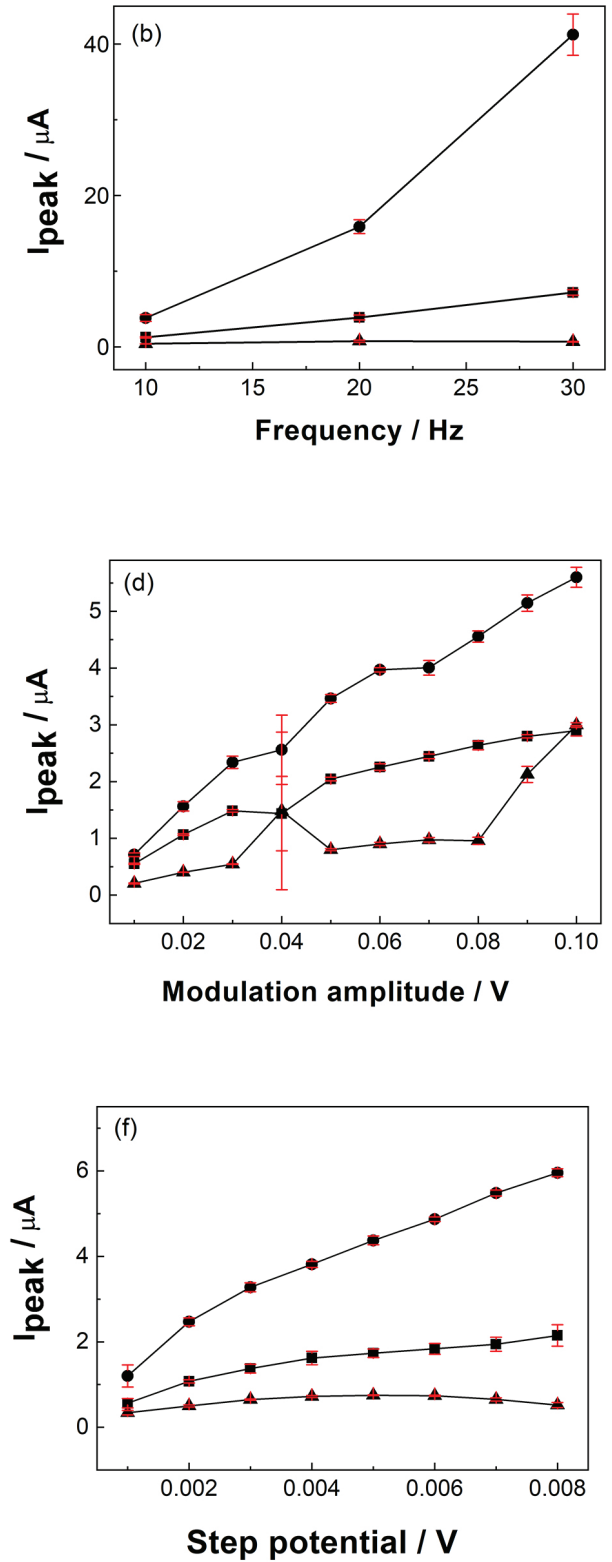

Figure 4. (a) Background-corrected SWASV recordings under different frequency values. SWASV parameters: $-0.4 \mathrm{~V}$ (deposition potential); $90 \mathrm{~s}$ (deposition time); $1500 \mathrm{rpm}$ (stirring rate); $0.004 \mathrm{~V}$ (step potential) and $0.03 \mathrm{~V}$ (modulation amplitude); (b) background-corrected SWASV recordings under different modulation amplitude values. SWASV parameters: $-0.4 \mathrm{~V}$ (deposition potential); $90 \mathrm{~s}$ (deposition time); $1500 \mathrm{rpm}$ (stirring rate); $0.004 \mathrm{~V}$ (step potential) and $10 \mathrm{~Hz}$ (frequency); (c) background-corrected SWASV recordings under different step potential values. SWASV parameters: -0.4 mV (deposition potential); $90 \mathrm{~s} \mathrm{(deposition} \mathrm{time);} 1500 \mathrm{rpm}$ (stirring rate); $0.03 \mathrm{mV}$ (modulation amplitude) and $10 \mathrm{~Hz}$ (frequency); effect of the (d) frequency, (e) modulation amplitude and (f) frequency on the voltammetric responses (stripping peak current ( $\mathrm{I}_{\text {peak }}$ )) of lead(II), copper(II), and mercury(II). Solution

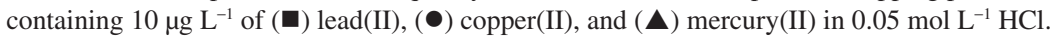

measurable and constant $\mathrm{I}_{\text {peak }}$, with relative standard deviation (RSD) of $1.9 \%$ for lead(II), 3.6\% for copper(II) and $2.7 \%$ for mercury(II). After the tenth measurement, the SPGE did not respond properly which indicated the loss of activity of the sensor.

\section{Analytical performance}

Based on the optimized SWASV experimental parameters in the previous steps, analytical curves were obtained correlating $\mathrm{I}_{\text {peak }}$ versus concentration of standard solutions of lead(II), copper(II) and mercury(II) in the concentration range between 5 and $45 \mu \mathrm{g} \mathrm{\textrm {L } ^ { - 1 }}$ (shown in Figure S5 and S6, SI section), employing $0.05 \mathrm{~mol} \mathrm{~L}^{-1} \mathrm{HCl}$ as supporting electrolyte. The main analytical parameters for the proposed method are presented in Table 2.

Table 3 shows a comparison of the proposed SWASV method with other methodologies reported in the literature for the determination of lead(II), copper(II) and mercury(II) regarding the working electrode type, metal 


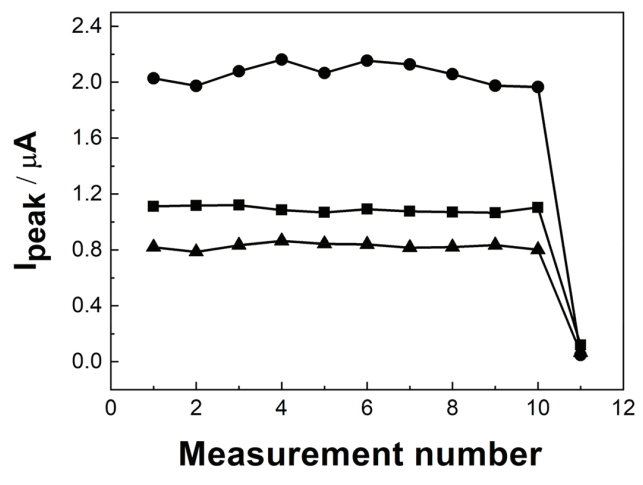

Figure 5. Variation of the peak current $\left(\mathrm{I}_{\text {peak }}\right)$ versus number of measurements $(\mathrm{n}=11)$ for a solution containing $10 \mu \mathrm{g} \mathrm{L} \mathrm{L}^{-1}$ of ( $(\mathbf{D})$ lead(II), (•) copper(II), and (A) mercury(II) in $0.05 \mathrm{~mol} \mathrm{~L}^{-1} \mathrm{HCl}$. SWASV parameters: $-0.4 \mathrm{~V}$ (deposition potential); $90 \mathrm{~s}$ (deposition time); $1500 \mathrm{rpm}$ (stirring rate); $0.03 \mathrm{~V}$ (modulation amplitude); $0.002 \mathrm{~V}$ (step potential) and $10 \mathrm{~Hz}$ (frequency).

ions, deposition time, linear range and limit of detection (LOD). The proposed protocol presents one of the shortest analysis times due to the shorter deposition times as the electrochemically-treated electrodes presented higher sensitivity and improved LOD values. Furthermore, only two other works ${ }^{16,18}$ are capable of performing the multi-element determination of lead(II), copper(II) and mercury(II), but employing deposition time higher than the proposed method. Hence, our proposed method presents shorter analysis time than the previous works leading to higher sample throughput. It is also noted that LOD values obtained in these studies were better than the values found in the individual determination of lead(II) ${ }^{25}$ and copper(II) ${ }_{,}{ }^{26}$ and better than the studies with modified SPEs. ${ }^{27,28}$ Thus, the proposed method employing electrochemically-treated SPGE enables rapid, direct and selective detection of lead(II), copper(II) and mercury(II) with satisfactory analytical response for the monitoring of trace metal in environmental samples, such as struvite.

\section{Interference study}

To evaluate the interference caused by other metals in the signals of lead(II), copper(II) and mercury(II), the interference study was performed at two interferent:analyte ratios (1:1 and 2:1) keeping the concentrations of the

Table 2. Analytical parameters for the determination of lead(II), copper(II) and mercury(II) by SWASV with SPGE

\begin{tabular}{lccc}
\hline Analytical parameter & Lead(II) & Copper(II) & Mercury(II) \\
\hline LWR / $(\mu \mathrm{g} \mathrm{L}-1)$ & 5 to 45 & 5 to 45 & 5 to 45 \\
Slope / $\left(\mu \mathrm{A} \mathrm{gg}^{-1} \mathrm{~L}\right)$ & $0.052 \pm 0.002$ & $0.088 \pm 0.001$ & $0.054 \pm 0.001$ \\
$\mathrm{LOD} /\left(\mu \mathrm{g} \mathrm{L}^{-1}\right)$ & 1.3 & 2.0 & 0.9 \\
$\mathrm{LOQ} /\left(\mu \mathrm{g} \mathrm{L}^{-1}\right)$ & 4.4 & 6.6 & 2.9 \\
$\mathrm{R}$ & 0.997 & 0.997 & 0.997 \\
\hline
\end{tabular}

LWR: linear working range; LOD: limit of detection; LOQ: limit of quantification; R: correlation coefficient.

Table 3. Comparison of the proposed method with some previously reported electrochemical methods for the determination of lead(II), copper(II) and mercury(II)

\begin{tabular}{|c|c|c|c|c|c|}
\hline Electrode & Metal ion & Deposition time / s & $\mathrm{LWR} /\left(\mu \mathrm{g} \mathrm{L}^{-1}\right)$ & $\mathrm{LOD} /\left(\mu \mathrm{g} \mathrm{L}^{-1}\right)$ & Reference \\
\hline \multirow{3}{*}{ SPGE } & $\mathrm{Pb}^{2+}$ & \multirow{3}{*}{240} & 5 to 300 & 1.2 & \multirow{3}{*}{18} \\
\hline & $\mathrm{Cu}^{2+}$ & & 5 to 300 & 1.0 & \\
\hline & $\mathrm{Hg}^{2+}$ & & 6 to 300 & 1.7 & \\
\hline \multirow{3}{*}{ SPGE } & $\mathrm{Pb}^{2+}$ & \multirow{3}{*}{120} & 0 to 50 & 0.5 & \multirow{3}{*}{16} \\
\hline & $\mathrm{Cu}^{2+}$ & & 0 to 50 & 2.0 & \\
\hline & $\mathrm{Hg}^{2+}$ & & 0 to 100 & 0.9 & \\
\hline SPGE & $\mathrm{Pb}^{2+}$ & 240 & 10 to 50 & 2.0 & 25 \\
\hline SPCE & $\mathrm{Cu}^{2+}$ & 60 & 0 to 63 & 5.5 & 26 \\
\hline $\mathrm{Au}-\mathrm{SPCE}$ & $\mathrm{Hg}^{2+}$ & 360 & 1 to 100 & 1.02 & 27 \\
\hline \multirow{2}{*}{ AuNP-SPGE } & $\mathrm{Pb}^{2+}$ & \multirow{2}{*}{120} & 20 to 200 & 2.2 & \multirow{2}{*}{28} \\
\hline & $\mathrm{Cu}^{2+}$ & & 20 to 300 & 1.6 & \\
\hline \multirow{3}{*}{ SPGE } & $\mathrm{Pb}^{2+}$ & \multirow{3}{*}{90} & \multirow{3}{*}{5 to 45} & 1.3 & \multirow{3}{*}{ this work } \\
\hline & $\mathrm{Cu}^{2+}$ & & & 2.0 & \\
\hline & $\mathrm{Hg}^{2+}$ & & & 0.9 & \\
\hline
\end{tabular}

LWR: linear working range; LOD: limit of detection; SPGE: screen-printed gold electrode; SPCE: screen-printed carbon electrode; Au-SPCE: gold modified screen-printed carbon electrode; AuNP-SPGE: screen-printed gold electrode modified with gold nanoparticles. 
analytes at $45 \mu \mathrm{g} \mathrm{L} \mathrm{L}^{-1}$ in $0.05 \mathrm{~mol} \mathrm{~L}-1 \mathrm{HCl}$ according to Table 4. The choice of metallic interferents (iron(III), nickel(II), zinc(II), cadmium(II) and cobalt(II)) was based on the possibility of being found in struvite. ${ }^{9,10}$

Table 4. Effects of additions of some interferents on the SWASV signals of $45 \mu \mathrm{g} \mathrm{L}{ }^{-1}$ lead(II), copper(II) and mercury(II)

\begin{tabular}{|c|c|c|c|}
\hline \multirow[b]{2}{*}{ Interferent } & \multirow[b]{2}{*}{ Analyte } & \multicolumn{2}{|c|}{ Current signal variation / \% } \\
\hline & & $\begin{array}{l}\text { Interferent:analyte } \\
\quad \text { ratio } 1: 1\end{array}$ & $\begin{array}{c}\text { Interferent:analyte } \\
\text { ratio } 2: 1\end{array}$ \\
\hline \multirow{3}{*}{$\mathrm{Fe}^{3+}$} & $\mathrm{Pb}^{\mathrm{II}}$ & -4.2 & -4.2 \\
\hline & $\mathrm{Cu}^{\mathrm{II}}$ & -12.4 & -33.4 \\
\hline & $\mathrm{Hg}^{\mathrm{II}}$ & +12.5 & -37.7 \\
\hline \multirow{3}{*}{$\mathrm{Ni}^{2+}$} & $\mathrm{Pb}^{\mathrm{II}}$ & -4.1 & +2.1 \\
\hline & $\mathrm{Cu}^{\mathrm{II}}$ & +28.3 & +12.2 \\
\hline & $\mathrm{Hg}^{\mathrm{II}}$ & +30.4 & +37.7 \\
\hline \multirow{3}{*}{$\mathrm{Zn}^{2+}$} & $\mathrm{Pb}^{\mathrm{II}}$ & -9.5 & -9.5 \\
\hline & $\mathrm{Cu}^{\mathrm{II}}$ & -33.4 & -35.5 \\
\hline & $\mathrm{Hg}^{\mathrm{II}}$ & -37.5 & -66.3 \\
\hline \multirow{3}{*}{$\mathrm{Cd}^{2+}$} & $\mathrm{Pb}^{\mathrm{II}}$ & +21.7 & +64.8 \\
\hline & $\mathrm{Cu}^{\mathrm{II}}$ & +23.4 & -28.2 \\
\hline & $\mathrm{Hg}^{\mathrm{II}}$ & -50.2 & -24.8 \\
\hline \multirow{3}{*}{$\mathrm{Co}^{2+}$} & $\mathrm{Pb}^{\mathrm{II}}$ & +0.9 & +33.4 \\
\hline & $\mathrm{Cu}^{\mathrm{II}}$ & -20.9 & -25.8 \\
\hline & $\mathrm{Hg}^{\mathrm{II}}$ & -24.6 & +37.2 \\
\hline
\end{tabular}

Table 4 shows that only iron(III), nickel(II) and zinc(II) in the 1:1 and 2:1 ratios did not significantly interfere with the lead(II) analytical signal, once the values are within the tolerable limit of $\pm 10 \%$ for interference in the signal. ${ }^{29}$ The other interferents showed significant interference with the lead(II) signal, except cobalt(II) in the proportions of $1: 1$. The decrease of the observed analytical signal is probably due to a competition of the metallic interferent investigated in the deposition step of the analytes. Although iron(III), nickel(II), zinc(II), cadmium(II) and cobalt(II) metals caused a significant change in the analytical signal of lead(II), copper(II) and mercury(II), no changes in their voltammetric profile were observed, so the standard addition method can circumvent the interference effects of these metals in the sample.

Determination of lead(II), copper(II) and mercury(II) in struvite

After obtaining the analytical parameters under optimized conditions, as a proof-of-concept, the proposed method was applied for the determination of lead(II),
copper(II) and mercury(II) in struvite, as indicated in Figure 6.

In the voltammograms shown in Figure 6a, we can observe that there are four peaks in the region corresponding to the analytes. As discussed earlier in Figure 1a, the peak at $0.02 \mathrm{~V}$ can be attributed to some contamination of the silver ink that is used in the manufacture of SPGE.${ }^{19}$ On the other hand, the addition of metal standards showed that the other peaks correspond to lead(II), copper(II) and mercury(II) in struvite. Afterwards, standard addition curves were then obtained for each metal as shown in Figures 6b-6d. However, from the analyses performed in the struvite sample, it was only possible to detect the concentrations of $1.70 \pm 0.30 \mu \mathrm{g} \mathrm{g}^{-1}$ of lead(II); however, this value is below the limit of quantification (LOQ) value so it is possible to affirm the detection of lead(II) as this value is above the LOD value. The concentration of other metals (copper(II) and mercury(II)) is below the respective LOD values by the proposed method. However, these LOD values are much lower than the limits established by the Brazilian regulatory agency,${ }^{30}$ which requires a maximum limit of metals in the order of $150 \mu \mathrm{g} \mathrm{g} \mathrm{g}^{-1}$ of lead(II) and $1.00 \mu \mathrm{g} \mathrm{g}^{-1}$ of mercury(II), for contaminants admitted on organic fertilizers and soil conditioners. It should be noted that the Brazilian regulatory agency does not stipulate restrictions for copper(II) since in trace concentrations it is considered as a micronutrient.

As it was not possible to determine copper(II) and mercury(II), the accuracy of the method was evaluated by means of the recovery test from the fortification of the sample with $10 \mu \mathrm{g} \mathrm{L}{ }^{-1}$ of a multielement (lead(II), copper(II) and mercury(II)) standard solution (final concentration for each metal in the cell corresponding to $16.67 \mathrm{mg} \mathrm{g}^{-1}$ in the real sample). After fortified, the lead(II), copper(II) and mercury(II) content was determined via SWASV previously optimized at SPGE using the standard addition method (shown in Figure S7, SI section). The results showed good agreement with the added concentration at 9.10, 9.20 and $11.10 \mu \mathrm{g} \mathrm{L}^{-1}$ with recovery values of $91 \pm 4 \%$ for lead(II), $92 \pm 2 \%$ for copper(II) and $111 \pm 2 \%$ for mercury(II), indicating the absence of matrix effect during the analysis.

\section{Conclusions}

The electroanalytical method proposed for the determination of metals in struvite using SWASV in combination with electrochemically treated SPGE enables the multielement determination of lead(II), copper(II) and mercury(II) in the concentration levels of $\mu \mathrm{g} \mathrm{L}^{-1}$. Satisfactory analytical parameters were obtained, highlighting improved LOD values in comparison with other electrochemical 

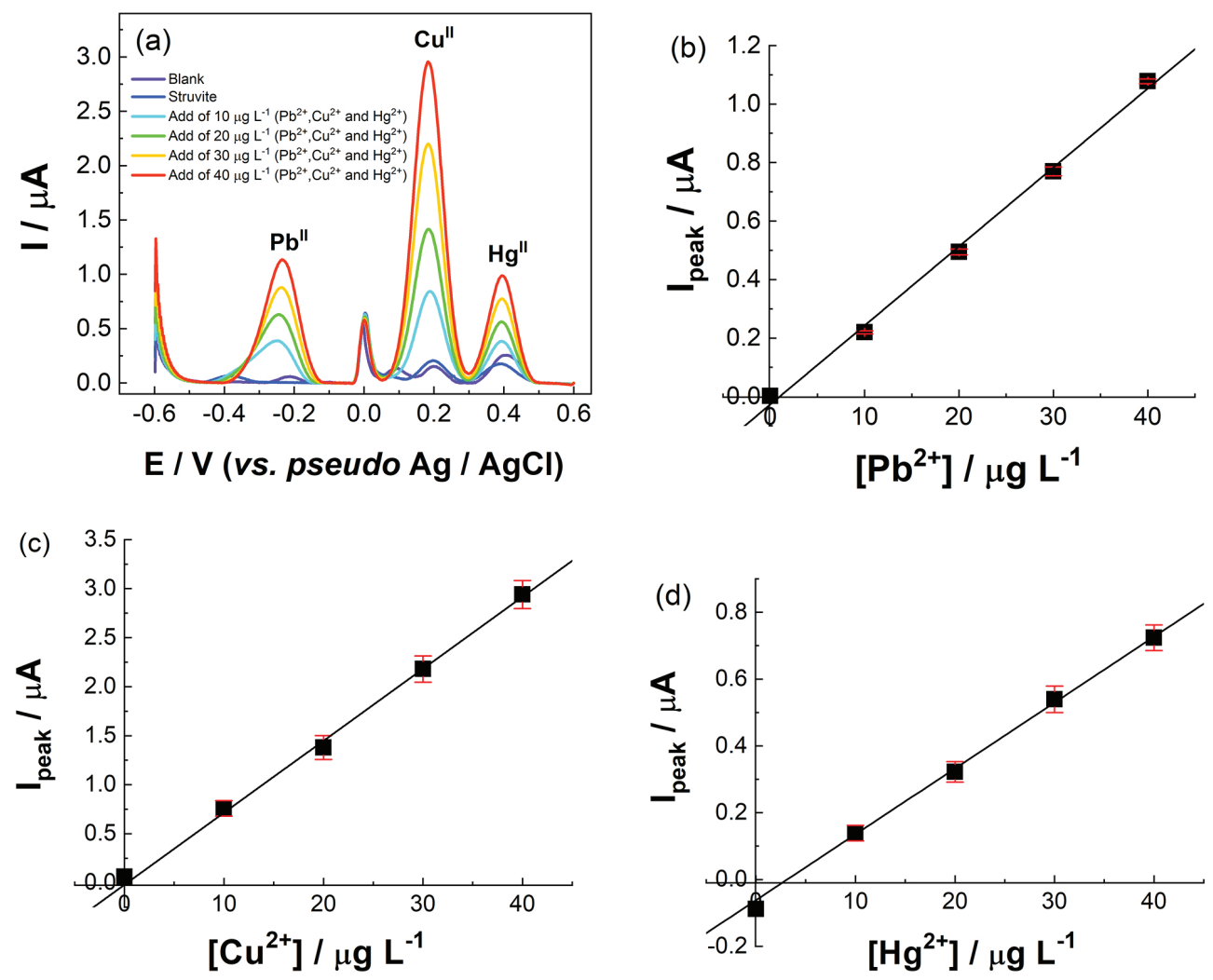

Figure 6. (a) Background-corrected SWASV recording for the lead(II), copper(II) and mercury(II) quantification in struvite sample and for four additions (10 to $40 \mu \mathrm{g} \mathrm{L} \mathrm{L}^{-1}$ ) of multielement (lead(II), copper(II) and mercury(II)) standard solution; (b) standard addition curve for lead(II) in struvite; (c) standard addition curve for copper(II) in struvite; and (d) standard addition curve for mercury(II) in struvite. SWASV parameters: $-0.4 \mathrm{~V}$ (deposition potential); $90 \mathrm{~s}$ (deposition time); $1500 \mathrm{rpm}$ (stirring rate); $0.03 \mathrm{~V}$ (modulation amplitude); $0.002 \mathrm{~V}$ (step potential) and $10 \mathrm{~Hz}$ (frequency). Background electrolyte: $0.05 \mathrm{~mol} \mathrm{~L}^{-1} \mathrm{HCl}$.

methods previously published, allowing the determination of these metals within the maximum limits required by the current Brazilian legislation. This high sensitivity can be attributed to the increase in surface roughness and consequently electroactive area of the electrode due to the electrochemical pretreatment of the SPGE. In addition, the proposed method presented satisfactory recovery values, indicating no interference from struvite matrix in the SWASV determinations. Therefore, this method shows sensitivity to trace analysis, has low cost and rapid responses and allows for simultaneous determination of lead(II), copper(II) and mercury(II) metals in struvite and be extended to the analysis of other samples.

\section{Supplementary Information}

Supplementary information is available free of charge at http://jbcs.sbq.org.br as PDF file.

\section{Acknowledgments}

The authors are grateful to FAPES/SEAG (No. 721/2016), FAPEMIG (PPM-00640-16), CNPq
(307271/2017-0 and 465389/2014-7 INCTBio) and CAPES (financial code 001) for financial support.

\section{Author Contributions}

Maria L. S. Vasconcellos was responsible for the data curation; formal analysis, investigation and methodology; Diego P. Rocha for the data curation, formal analysis, investigation, methodology and writing original draft; Sílvia V. F. Castro for the formal analysis, investigation and methodology; Luiz R. G. e Silva for the data curation and methodology; Rodrigo A. A. Muñoz for the conceptualization, funding acquisition, project administration, resources, supervision, writing review and editing; Marcos B. J. G. Freitas for the validation and writing original draft; Rafael Q. Ferreira for the conceptualization, funding acquisition, project administration, resources, supervision, writing review and editing.

\section{References}

1. Ehlers, E.; Agricultura Sustentável: Origens e Perspectivas de um Novo Paradigma, $2^{\text {nd }}$ ed.; Agropecuária: Guaíba, 1999. 
2. International Federation of Organic Agriculture Movements (IFOAM); Normas Básicas para a Produção e Processamento de Alimentos Orgânicos; IFOAM: Bonn, 1998.

3. Mazzoleni, E. M.; Nogueira, J. M.; Rev. Econ. Sociol. Rural 2006, 02, 263.

4. Tansel, B.; Lunn, G.; Monje, O.; Chemosphere 2018, 194, 504.

5. Jönsson, H.; Stintzing, A. R.; Vinneras, B.; Salomon, E.; Guidelines on the Use of Urine and Faeces in Crop Production; Stockholm Environment Institute: Sweden, 2004.

6. Guzha, E.; Nhapi, I.; Rockström, J.; Phys. Chem. Earth, Parts $A / B / C 2005,30,840$.

7. Heinonen-tanski, H.; Wijk-sijbesma, C.; Bioresour. Technol. 2005, 96, 403.

8. Pradhan, S. K.; Holopainen, J. K.; Weisell, J.; Heinonen-Tanski, H.; J. Agric. Food Chem. 2010, 58, 2034.

9. Ryu, H. D.; Lim, C. S.; Kim, Y. K.; Kim, K. Y.; Lee, S. I.; Environ. Eng. Sci. 2012, 29, 540.

10. Antonini, S.; Paris, S.; Eichert, T.; Clemens, J.; Clean: Soil, Air, Water 2011, 39, 1099.

11. Santos, L. H. M. L. M. A.; Araujo, N.; Fachini, A.; Pena, A.; Delerue-matos, C.; Montenegro, M. C. B. S. M.; J. Hazard. Mater. 2010, 175, 45.

12. Brett, C. M. A.; Brett, A. M. O.; Electroanalysis; Oxford University Press: Oxford, 1998.

13. Renedo, O. D.; Alonso-Lomillo, M. A.; Arcos-Martinez, M. J.; Talanta 2007, 73, 202.

14. Squissato, A. L.; Almeida, E. S.; Silva, S. G.; Richter, E. M.; Batista, A. D.; Munoz, R. A. A.; TrAC, Trends Anal. Chem. 2018, 108, 210.

15. Nascimento, V. B.; Angnes, L.; Quim. Nova 1998, 21, 5.

16. Laschi, S.; Palchetti, I.; Mascini, M.; Sens. Actuators, B 2006, $114,460$.

17. Bernalte, E.; Marín-Sanchez, C.; Pinilla-Gil, E.; Anal. Chim. Acta 2011, 689, 60.
18. Almeida, E. S.; Richter, E. M.; Munoz, R. A. A.; Anal. Chim. Acta 2014, 837, 38.

19. Squissato, A. L.; Rocha, D. P.; Almeida, E. S.; Richter, E. M.; Munoz, R. A. A.; Electroanalysis 2018, 30, 20.

20. Tormin, T. F.; Oliveira, G. K. F.; Richter, E. M.; Munoz, R. A. A.; Electroanalysis 2016, 28, 940.

21. Li, M.; Li, Y. T.; Li, D. W.; Long, Y. T.; Anal. Chim. Acta 2012, $734,31$.

22. Fornasiero, P.; Cargnello, M.; Morphological, Compositional, and Shape Control of Materials for Catalysis. Studies in Surface Science and Catalysis; Elsevier: Amsterdam, The Netherlands, 2017.

23. Nobre, A. L. R.; Mazo, L. H.; Quim. Nova 1997, 20, 412.

24. Bernalte, E.; Marín-Sanchez, C.; Pinilla-Gil, E.; Sens. Actuators, B 2012, 161, 669 .

25. Noh, M. F. M.; Tothill, I. E.; Anal. Bioanal. Chem. 2006, 386, 209.

26. Faucher, S.; Cugnet, C.; Authier, L.; Lespes, G.; Anal. Methods 2014, 6, 7942.

27. Somé, I. T.; Sakira, A. K.; Mertens, D.; Ronkart, S. N.; Kauffmann, J.-M.; Talanta 2016, 152, 335.

28. Wan, H.; Sun, Q.; Li, H.; Sun, F.; Hu, N.; Wang, P.; Sens. Actuators, B 2015, 209, 336.

29. Squissato, A.; Richter, E. M.; Munoz, R. A. A.; Talanta 2019, $201,433$.

30. Ministério da Agricultura, Pecuária e Abastecimento/Secretaria de Defesa Agropecuária (MAPA/SDA); Instrução Normativa No. 07, de 12 de abril de 2016, Diário Oficial da União (DOU), Brasília, No. 82, de 02/05/2016, p. 9.

Submitted: January 14, 2020 Published online: May 5, 2020 